\title{
Zika virus congenital syndrome: experimental models and clinical aspects
}

\author{
Carolina Manganeli Polonio, Carla Longo de Freitas, Nagela Ghabdan Zanluqui and Jean Pierre Schatzmann Peron*
}

\begin{abstract}
Viral infections have long been the cause of severe diseases to humans, increasing morbidity and mortality rates worldwide, either in rich or poor countries. Yellow fever virus, H1N1 virus, HIV, dengue virus, hepatitis B and C are well known threats to human health, being responsible for many million deaths annually, associated to a huge economic and social cost. In this context, a recently introduced flavivirus in South America, called Zika virus (ZIKV), led the WHO to declare in February 1st 2016 a warning on Public Health Emergency of International Concern (PHEIC). ZIKV is an arbovirus of the Flaviviridae family firstly isolated from sentinels Rhesus sp. monkeys at the Ziika forest in Uganda, Africa, in 1947. Lately, the virus has well adapted to the worldwide spread Aedes aegypti mosquito, the vector for DENV, CHIKV, YFV and many others. At first, it was not considered a threat to human health, but everything changed when a skyrocketing number of babies born with microcephaly and adults with Guillain-Barré syndrome were reported, mainly in northeastern Brazil. It is now well established that the virus is responsible for the so called congenital Zika syndrome (CZS), whose most dramatic features are microcephaly, arthrogryposis and ocular damage. Thus, in this review, we provide a brief discussion of these main clinical aspects of the CZS, correlating them with the experimental animal models described so far.
\end{abstract}

Keywords: Zika virus, Congenital infection, Arthrogryposis, Ocular abnormality, Experimental models

\section{Background}

Since the first semester of 2015, Brazil has experienced some unprecedented epidemics of babies born with microcephaly as well as of adults with peripheral flaccid paralysis, suggestive of Guillain-Barré syndrome (GBS). The first cases were detected in the states of Bahia, Pernambuco and Paraíba, which are still now the epicenter of the crisis. Although many possibilities were considered, it is now well established that both are caused by a recently introduced virus named Zika virus (ZIKV) [1-4].

The ZIKV is an arbovirus that belongs to the Flaviviridae family. It was first isolated from sentinels Rhesus sp. monkeys from the Ziika forest in Uganda, Africa, in 1947 [5]. Further, the virus was also isolated from the sylvatic vector, a mosquito of Aedes africanus species. Interestingly, the virus has well adapted to other species of mosquitoes, but most importantly to Aedes aegypti [6], widely spread through the globe, and a well-known vector for

\footnotetext{
* Correspondence: jeanpierre@usp.br

Neuroimmune Interactions Laboratory, Immunology Department - ICB IV,

University of São Paulo (USP), Av. Prof. Lineu Prestes, 1730, Cidade

Universitária, São Paulo, SP CEP 05508-900, Brazil
}

many other viruses, including dengue (DENV), West Nile (WNV), yellow fever (YFV), chikungunya (CHV), Japanese encephalitis (JEV) and many others $[7,8]$.

ZIKV genome is composed of a positive single-stranded RNA that codifies three structural proteins, capside (C), pre-membrane (Pr-M) and envelope (Env), and seven non-structural proteins, NS1, NS2a-2b, NS3, NS4a-4b and NS5 [9]. The biological function of these proteins, either in the invertebrate or in vertebrate hosts have just started to be elucidated. Whereas structural proteins are important molecules for cell invasion [10-12], and to induce the immune response, non-structural proteins are important for viral replication and immune response evasion [13, 14]. Recently, it was shown that ZIKV infectivity of Aedes aegypti depends on NS1 antigenemia. Interestingly, the Asian strain is much more infectious to mosquitoes than the African strain, mainly due to an alanine-tovaline amino acid substitution at the residue 188 of the NS1 [15].

Although ZIKV is considered an emerging infectious disease, it has been neglected for many years since human infection was early reported in Africa and Asia 
[9]. Initially, it was not considered a threat to human health, as the infection was considered mild and benign. In 2007, at the Yap Island, Micronesia, ZIKV infection started to reach a wider and more pronounced spectrum. A large number of people presented symptoms like moderate fever $\left(37.8\right.$ to $39.5{ }^{\circ} \mathrm{C}$ ), headaches, arthralgia on hands and feet, conjunctivitis and cutaneous rash. These patients were erroneously diagnosed with DENV, but soon later it was discovered to be the first ZIKV outbreak in history [16]. Thus, differential signs and symptoms of each patient must be evaluated cautiously, as due to the similarity with other Flavivirus infections such as dengue and chikungunya, ZIKV infection may be misdiagnosed. A summarized list of differential diagnosis, laboratory tests and patient managing protocols have been elaborated [17].

Further ZIKV outbreaks have been reported in many countries. The first one happened in French Polynesia in 2014, with more than 28,000 people infected [18]. Outbreaks were also reported in Tahiti [19] and New Caledonia [20]. In fact, ZIKV has been recently found in 69 countries worldwide, according to the World Health Organization (WHO) [21]. What is worthy to mention is the fact that, although a great number of people was infected by ZIKV in French Polynesia, at that time, no increase in the rates of babies born with microcephaly, neither in adults with GBS was reported. Interestingly, however, a retrospective analysis revealed that indeed there was a significant increase in the microcephaly rate per live births in French Polinesia in 2014 [22].

The relevance of ZIKV infection during pregnancy has gained great notoriety since the huge increase in the number of babies born with microcephaly, especially in the northeast of Brazil. Because of that, on February 1st 2016 the WHO declared a Public Health Emergency of International Concern (PHEIC). Nowadays, according to the Brazilian Ministry of Health, there are 2660 babies born with microcephaly caused by ZIKV, and yet about 6000 cases have to be confirmed. Bahia (433 cases), Pernambuco (408 cases) and Paraíba (191 cases) states are the most affected [23].

It is now well accepted that microcephaly is only one of the features of the so-called congenital Zika syndrome (CZS). Despite being unquestionably the most dramatic, infants may also display several other problems, such as arthrogryposis, intrauterine growth restriction (IURG), uveitis and retinal degeneration [3, 24]. In fact, it has been recently shown that even babies born without microcephaly may display serious brain lesions [24].

\section{Zika virus and microcephaly}

Since the second semester of 2015, due to the increased incidence of microcephaly in Brazil, many researchers and physicians suggested a causal relation between them, although there were no clinical or experimental evidences to support this statement. One of the first strong evidence of causal relation between ZIKV and microcephaly was reported in March, 2016. A woman working as a volunteer in Natal, capital of Rio Grande do Norte state in Brazil, had become pregnant in February, 2015. At the 13th gestational week, she had high fever, severe musculoskeletal and retroocular pain and maculopapular rash. Exams performed until 20th gestational week revealed no fetal alterations. Nevertheless, at 29 weeks of gestation, the patient returned to Europe, and examinations revealed the first signs of fetal damage, which was confirmed at 32 weeks. Ultrasound showed IURG associated with placental-artery calcification. Brain imaging evidenced cortical and subcortical calcifications with moderate ventriculomegaly, smaller cerebellum and brain stem, resulting in a head circumference below $26 \mathrm{~cm}$, which indicates microcephaly. Due to the high degree of fetal damage, the decision on interrupting the pregnancy was made.

Post-mortem evaluation of fetal tissue revealed PCR positive for ZIKV whereas negative to other flavivirus (DENV, YFV, WNV and tick-borne encephalitis virus). Complete ZIKV genome was recovered from the brain tissue with $99.7 \%$ identity to ZIKV Asian strain originated from French Polynesia, which happens to be the strain currently circulating in Brazil. Anatomical and histological analyses showed loss of gyration of the cortex, left ventricle collapsed and right ventricle dilated. This was associated with astroglyosis in the subarachnoid space, slight infiltrated cells and viral particles in neuronal cytoplasm [25]. Another interesting case control study was carried out in eight public hospitals of Recife, Pernambuco state, Brazil, with neonates born during the period of January, 2016 to May, 2016. The study group was divided according to these criteria: newborns with microcephaly, defined as head circumference smaller than the average for sex and gestational age; and control group, newborns that presented no brain abnormalities. Besides that, the babies were divided into groups related to the gestational age: born at 37 weeks or more, born at 34 weeks or less and born between 34 and 36 weeks. Cerebrospinal fluid samples of the newborns and serum from the mothers were tested for African and Asian ZIKV by RT-PCR.

Results showed that $80 \%$ of the mothers had ZIKV infection, and $41 \%$ of newborns tested positive for ZIKV, evidencing the congenital ZIKV infection [26]. Further reports corroborated these findings, and the virus was already detected in placenta [27], cerebrospinal fluid [25] and retina [28] of microcephalic infants. Besides, a study with 44 women infected with ZIKV during gestation showed that the ZIKV was found in Hoffbauer cells of the placenta, and this may play a role in the dissemination of the virus during the first trimester and, thus, 
responsible for transferring ZIKV to the fetal brain [29]. Altogether, clinical findings were in great consonance with the fact that ZIKV is the actual etiological agent of microcephaly.

However, it was suggested that other factors could be causing microcephaly; since such correlation had never been determined for a flavivirus. For instance, some suggested that microcephaly could be caused by yellow fever vaccination during pregnancy, by the exposure to an insecticide to kill mosquito larvae, previous infection with DENV or even due to nutritional state of the mothers. Thus, at that moment, the direct causal correlation between ZIKV and microcephaly had yet to be determined, and experimental methods were the best approach.

In this context, on May 11th, 2016, three reports were published concomitantly using murine experimental models to clarify the relationship between ZIKV and microcephaly. One of the studies used the ZIKV strain isolated from French Polynesia under two experimental approaches: female $\mathrm{C} 57 \mathrm{Bl} / 6$ IFNAR1 ${ }^{-} /^{-}$crossed with wild type males; and wild type females treated with MAR1-5A3, an IFNAR1 antibody blocker. These models were chosen in order to facilitate viral replication, since type I interferons, as IFN- $\alpha / \beta$, play an important role in antiviral responses, as previously demonstrated for several flaviviruses [30].

In the first approach, female mice were subcutaneously infected with $10^{3} \mathrm{FFU}$ at 6.5 and 7.5 days of gestation. Analysis were performed at days P13.5 and P15.5 for viral titers, fetal body measures and cerebral histology. The pups suffered from dramatic abnormalities, such as intrauterine growth restriction (IUGR) and the presence of necrotic tissue in the placenta and brain, associated with a high rate of abortion and fetal resorption. However, there were no evident signs of microcephaly. PCR tests for ZIKV were positive in placenta and brain. On the second model, females were treated with the IFNARI blocker MAR1-5A3 at 5.5 days of gestation, infected at day 6.5 and analyzed as mentioned. IUGR was less evident and no abortion occurred. However, the presence of the virus was detected in fetal brain, and the viral titers were inversely proportional do the amount of antiIFNRA1 used. Moreover, the research also shed light on the mechanisms of ZIKV infection on the placental compartment. Spongiotrophoblasts and glycogen trophoblasts were infected by the virus, and this was correlated with placental damage and apoptosis [30].

Another group performed the injection of ZIKV SZ01 at cerebroventricular space/lateral ventricle (LV) at day 13.5 of gestation, to circumvent mother immune response against the virus. Although this approach may not prove the vertical transmission of the virus, it may help to elucidate the mechanisms of neuronal damage. At P16.5 the presence of the virus in the brain of the pups was confirmed on the ventricular (VZ) and subventricular zones (SVZ), where most of neuronal precursor cells (NPCs) are located. Results demonstrated a significant reduction of NPCs as determined by immunofluorescence of $\mathrm{TBR}^{+}, \mathrm{SOX}^{+}$and $\mathrm{FOXP} 2^{+}$cells, which colocalized active caspase- 3 . This was associated with reduction of the thickness of cortical plate $(\mathrm{CP}), \mathrm{VZ}$ and SVZ areas of the brain, resulting in overall reduction of the brain size [31].

With the aim of identifying genes that could be master regulators for microcephaly, the group performed RNA sequencing of brain samples from infected and noninfected dams. As expected, data indicated a significant upregulation of genes involved in antiviral immune response, especially cytokines, chemokines and many interferon stimulating genes (ISGs). This is in accordance with the fact that the virus is present in the brain, and thus, eliciting a local immune response. Whether this response is mainly mounted by resident glial cells or by peripheral infiltrating leukocytes has to be determined. It was also shown that many genes involved in cell cycle were greatly altered by the presence of the virus. Thus, it is plausible to speculate that, besides inducing inflammation, this deregulation, directly or not, may greatly account for the apoptotic cell death of NPCs. The group also evaluated the expression of genes correlating directly with microcephaly, which demonstrates that many of them were downregulated. The role of these genes and phenomena orchestrated by them during ZIKV infection has still to be determined.

It is noteworthy that all the models described so far, either used IFNAR deficient animals or anti-IFNAR treatment in order to circumvent the mother innate antiviral immune response and, thus, allow virus replication and dissemination throughout the fetal body. Although these are precious and valuable approaches, they may not be ideal, as viral titers may reach very high concentration, which may not be physiological. In this sense, our group used wild-type SJL mice, which had previously shown to be susceptible to neurotropic viral infection, mainly due to their reduced production of type I interferons [32].

Thus, female SJL pregnant mice were infected intravenously with a Brazilian ZIKV isolate between days E10-E13. The findings were very consistent and corroborated by those previously mentioned [27, 28]. Pups from infected mothers presented significant IUGR, with reduced measurements for size and weight, cranial height, biparietal and crown rump length. Histological analysis was performed in several different areas of the brain, showing a reduced cortical layer thickness and intranuclear vacuolization, with chromatin margination in the cortex, thalamus and hypothalamus. No alterations 
were observed in cerebellum and hippocampus. This was associated with high viral titers in the brains of the pups, although it was also detected in the liver and spleen. Interestingly, we observed that infected pups also had an impaired eye formation, which was further corroborated by both experimental and clinical observations [26, 27], which will be further discussed.

In search for the mechanisms through which brain lesions were established, RNA expression targeting genes for apoptosis and autophagy was performed. Interestingly, a high increase in the expression of pro-apoptotic and autophagy genes, such as BMF, IRGM and Bcl6, was observed, supporting previous findings either in the brains of the pups or in the cultures of fibroblasts infected with ZIKV [10]. Not surprisingly, when the same set of experiments was performed with C57BL6 mice, it was clear that the virus was not able to cross the placenta and reach the fetus. PCR for ZIKV was negative and there were no macroscopic nor morphological alterations in the brain of the pups. This brings to discussion the fact that the genetics of the host is very important for the outcome of the disease. Also, it is validated by clinical observations indicating that around $30 \%$ of infected pregnant women will have babies with microcephaly [3]. In this sense, further studies on the mechanisms of resistance to ZIKV-induced congenital syndrome in human subjects need to be addressed. This kind of approach would reveal why the northeast of Brazil is still the epicenter of the epidemic and, besides, would shed light on mechanisms that may be explored by therapeutic interventions.

\section{ZIKV and clinical aspects}

According to the WHO, children that develop microcephaly display impaired mental and intellectual ability, difficulty in motor coordination, postural balance and language. In more severe cases, they may also present seizures, epilepsy and muscle stiffness [23]. As these features are the result of the severe impairment or malformation of the brain, it is possible to correlate clinical manifestations of microcephaly children with the findings in experimental models [32]. The hypothalamus is responsible for assisting the control of the autonomous nervous system by commanding vital functions such as the respiratory and circulatory systems, body temperature, and even food intake and digestion. The thalamus is responsible for transmission of sensory impulses to the cortex, playing an important role in cognition, consciousness and control of autonomous activities. The cortex has plenty of ascending neurons responsible for memory, attention, consciousness, language, perception and thoughts. Thus, being the cortex, thalamus and hypothalamus the most affected regions during ZIKV infection, it is very understandable the presence of the aforementioned signs and symptoms in infected babies.

Several studies on the clinical aspects of the CZS have been published. A study showed anomalies observed in children of 16 pregnant women infected by ZIKV during gestation. Nine of these women had the virus in the amniotic fluid, seven had the virus in the umbilical cord blood and one in the placenta. Among these alterations, it is noticeable the loss of cerebral parenchyma volume, followed by polymicrogyria, a cortical malformation characterized by irregular and small gyration of the cortex. Moreover, anomalies in the corpus callosum like agenesia and dysgenesia, ventriculomegaly, lysencephaly, periventricular and cortical calcifications, at the junction of the white and gray mass and brainstem are present in some cases [33].

Another report with 11 newborns showed similar findings as the previous group cited, describing lisencephaly, atrophy, taquigyria, enlargement of hemisphere space and subrachnoid, shallow sulci, cortical polymicrogyria, hypoplasia of cerebellum and brain stem [34]. Histopathological findings corroborated previous observation of a gliosis outbursting pial limits with perivascular calcifications, usually associated with few infiltrating macrophages $[35,36]$.

One of the questions that remained unclear was if there were differences on neurological alterations among pregnant women infected in different periods of gestation. A study published in 2016 evaluated two pregnant women who had symptoms related to ZIKV infection during the 36th gestational week. The first patient was negative for TORCHES (toxoplasmosis, rubella, cytomegalovirus, herpes and syphilis) and DENV, while the second patient presented IgM and IgG for toxoplasmosis during 9th and 18th weeks of pregnancy. Besides that, both patients were positive for ZIKV in serum and urine samples. At birth, by the 38th and 39th weeks, respectively, the children were positive for ZIKV, confirming the vertical transmission, although with normal cephalic circumference and lacking ocular alterations. The transfontanellar ultrasound showed subependymal cysts and lenticulostriate vasculopathy. Although these alterations are not well understood, it indicates that ZIKV infection even during late phase of gestation may be deleterious to the babies [37]. In fact, many neurological findings have been described even in infants without microcephaly, as cortical lesions and calcifications, associated or not with cerebellar and spinal cord damage. The consequences are hyperreflexia, seizures, dysphagia, and also vision and hearing loss $[38,39]$. These alterations may be more related to infection during the last trimester of gestation.

\section{Arthrogryposis}

Although microcephaly has received major attention, ZIKV infection during pregnancy also leads to other 
malformations. These include mainly ocular and musculoskeletal abnormalities, such as retinal degeneration and craniofacial abnormalities with joint contractures called arthrogryposis, and in some cases, associated with spontaneous abortion [40, 41].

Arthrogryposis, first described in 1841, is defined as a congenital, non-progressive, joint contracture that affects two or more areas of the body. It is agreed that arthrogryposis is secondary to several maternal or fetal diseases, mainly those that restricts fetal movement in the uterus [42]. This reduction induces fibrosis of the joints and musculoskeletal tissues, resulting in severe limb contractures and features as clubfoot, rotated shoulder, palmar and interphalangeal contractures, arachnodactyly and several others. Although its molecular mechanisms are still under debate, genetic mutations of beta-tropomyosin, type 2 troponin, myosin heavy chain 3, myosin binding protein 1 are examples of the genetic correlation with arthrogryposis [43-45]. Moreover, neurological abnormalities of the fetus, either central - such as hydrocephaly, microcephaly, ventriculomegaly - and peripheral or neuromuscular maldevelopment, correlate to about $70-80 \%$ of the cases of arthrogryposis [46].

Either infectious or non-infectious maternal diseases may be responsible for the establishment of arthrogryposis. For example, diabetes mellitus, multiple sclerosis and myasthenia gravis or TORCH infections may greatly account [46-51]. Recently, along with microcephaly, arthrogryposis has been widely correlated with CZS. The mechanisms, however, have not been elucidated, but are likely to be consequence of the viral neurotropism, resulting in brain damage that interferes with adequate neuronal development and subsequent impaired neuromuscular signaling triggering reduction of intrauterine mobility [40,52].

From August to October 2015, in a group of 35 infants with microcephaly related with ZIKV infection, at least $11 \%$ of them had arthrogryposis, which evidenced central or peripheral nervous system involvement. Furthermore, 25 infants (74\%), had severe microcephaly and 11 (31\%) presented with excessive and redundant scalp skin [53].

Martines et al. [35] presented three cases of birth followed by death of newborns whose mothers were infected with ZIKV during pregnancy. These infants had several congenital malformations, including muscle contractures, craniofacial disorders, pulmonary hypoplasia and brain abnormalities. These manifestations are characteristic of the dramatic impact of fetal ZIKV infection. Another report showed that an ultrasound test performed on a 20-year-old woman at the 18th week of gestation showed fetal weight below the mean value for gestational age. Ultrasound examinations performed at the 26th and 30th gestational week revealed microcephaly, hydranencephaly with minimal residual cortical parenchyma and, at the 32nd gestational week, undergone fetal demise. The woman passed through an induced labor and delivered a female fetus with a weight of $930 \mathrm{~g}$ presenting dramatic microcephaly and arthrogryposis. ZIKV was detected in extracts of cerebral cortex, medulla oblongata and cerebrospinal and amniotic fluid [54].

In another study, a Spanish group demonstrated that at 19th week of gestation, the ultrasound examination revealed fetal malformations and the ZIKV was detected in the amniotic fluid. The pregnancy was terminated at week 21. The autopsy of the fetus revealed bilateral hydrocephalus, cerebral microcalcifications and severe arthrogryposis. The skeletal muscles were underdeveloped and suffered fatty replacement, with fibrosis of the interarticular spaces. In addition, the fetus also presented hydrocephalus, dilatation of both lateral ventricles and cerebral calcifications, nevertheless, without microcephaly. ZIKV was detected in the umbilical cord and brain tissue of the fetus [55].

In summary, along with microcephaly, arthrogryposis is among the most severe features of the CZS, resulting in great impact on the lives of mothers and babies. Besides the fact that its mechanisms must be determined, there are many questions to be addressed. For example, is there a correlation between ZIKV strain, host genetics and arthrogryposis? Was there an increase in arthrogryposis in previous outbreaks, as in French Polynesia? Is there a peripheral nervous system component for the ZIKV-associated arthrogryposis?

\section{Ocular alterations}

Ophthalmic findings in infants born from ZIKV infected mothers have been very usual in newborns with or without microcephaly during the outbreak in Brazil. It has been demonstrated that more than $80 \%$ of the infants with microcephaly examined from Recife, Bahia and São Paulo states had ophthalmoscopic abnormalities [56-58]. The first report describing ocular findings showed three children with microcephaly associated with macular pigment mottling and one of them presented a characteristic macular neuroretinal atrophy [26]. Their mothers reported symptoms such as rash and arthralgia during the first semester of pregnancy, corroborating the susceptibility period [59]. Although no real-time PCR test was performed, all TORCH infections were ruled out, and the authors declared that those cases comply criteria for ZIKV vertical transmission since cerebral calcification was detected by computed tomography scan, suggesting intrauterine infection.

Interestingly, the same group further reported ocular damage in an infant without microcephaly. Although the mother did not refer ZIKV-related symptoms during pregnancy, the newborn presented hyperreflexia at birth. Further ultrasound analysis revealed ventriculomegaly, 
lissencephaly and calcifications of the basal ganglia. This highlights the fact that ocular impairment is not necessarily associated with microcephaly, requiring a refined clinical evaluation [24].

Another study revealed that after retinal evaluation of 10 children with microcephaly, not only macular atrophy, but also optic nerve hypoplasia, pallor, foveal reflex loss associated with mild to moderate pigment mottling were present. As it is known that WNV can lead to macular injuries and cytomegalovirus can cause optic nerve alterations, serology tests for toxoplasmosis, rubella, cytomegalovirus, herpes simplex, syphilis and human immunodeficiency virus (HIV) were performed for all infants and the results were negative [60].

In a more substantial study, 55 infants who had mistrusted or stablished microcephaly due to presumed ZIKV congenital infection were submitted to ophthalmic assessment [61]. From the 55 children, 24 had their cerebrospinal fluid tested by IgM antibody-capture Elisa (MAC-ELISA) for ZIKV and DENV and all of them were positive for ZIKV. From the 22 remaining children, 14 presented ophthalmoscopic findings, stablishing the correlation between ZIKV and ocular findings.

Although ZIKV has been associated with ophthalmic injuries, it was still unclear if ocular alterations occurred solely in newborns with microcephaly. Ventura et al. [57], described a 57-day-old and a 6-day-old infant positive for ZIKV IgM antibody-capture Elisa in the cerebral spinal fluid associated with chorioretinal scar on the macular region and optic nerve lesion, corroborating previous findings $[26,57]$. However, remarkably, microcephaly was absent in these cases [24, 62]. These reports emphasize that microcephaly is not a mandatory criterion to determine congenital ZIKV infection diagnosis, since other ZIKV-related injuries may occur.

Despite the concern with the newborns, adults may also present ocular damage associated with ZIKV infection. Non-purulent conjunctivitis and retro-orbital hyperemia are common symptoms [63]. Also, uveitis was observed in a 40-year-old man diagnosed with ZIKV [64], whose aqueous humor was positive for ZIKV RNA. Furthermore, a case of bilateral hypertensive iridocyclitis was also reported in a 39-years-old woman clinically diagnosed with ZIKV infection [65]. After the presence of classic signs of fever and rash, the patient presented bilateral ocular discomfort, blurry vision and mild redness. Very unexpectedly, a case report showed that ZIKV particles were found in the tears of a 76-year-old patient that succumbed to infection, probably due to the very high viral titers, $2.10^{8}$ viral particles per $\mathrm{mL}$. A visiting relative swiped the tears of the patient, which was the only close contact referred, and 1 week later presented ZIKV infection symptoms, raising the question whether non-vector transmission of $\mathrm{ZIKV}$ is a real problem to immunocompetent hosts.
In fact, it is already well demonstrated that ZIKV may be sexually transmitted [21]. However, body fluids had never been associated with arbovirus infections before. In summary, ophthalmological alterations and injuries due to ZIKV infection are not restricted to infants, either with or without microcephaly, and may affect adults as well. These ocular findings are potential manifestations of ZIKV infection and the symptoms should not be neglected [66].

The mechanisms through which ZIKV causes ocular damage have started to be elucidated in experimental models. Through the infection of pregnant IFNARI deficient mice or wild type mice treated with anti-IFNARI monoclonal antibodies, it was demonstrated that the virus targets the retina, iris and optic nerve causing panuveitis and the shedding of viral particles in the tears at $3.10^{2} \mathrm{FFUs} / \mathrm{mL}$. Even after 28 days of infection and clearance of the virus in the serum, ZIKV was still detected in the eye and tears. Infectivity of the particles were confirmed after inoculation with eye homogenates

Table 1 Clinical aspects of newborns from infected mothers with Zika virus during pregnancy

\begin{tabular}{ll}
\hline Abnormalities & References \\
\hline Brain & {$[3,24,34]$} \\
Ventriculomegaly & {$[3,24,34,36,37,39,40,56]$} \\
Cortical and subcortical calcifications & {$[3,34,35]$} \\
Agyria, taquigyria or polymicrogyria & {$[3,56]$} \\
Collapsed or dilated ventricle & {$[34]$} \\
Agenesia & {$[24,34]$} \\
Lysencephaly & {$[35]$} \\
Hypoplasia of cerebellum & {$[55,56]$} \\
Hydranencephaly & {$[34]$} \\
Loss of cerebral parenchyma volume & {$[3]$} \\
Astroglyosis & {$[24]$} \\
Ocular & {$[24]$} \\
Uveitis & {$[28]$} \\
Retinal degeneration & {$[60]$} \\
Neuroretinal atrophy & {$[58,60]$} \\
Macular atrophy & {$[28]$} \\
Optic nerve hypoplasia & {$[28,58]$} \\
Macular pigment mottling & {$[36-56]$} \\
Chorioretinal scar & \\
Others & {$[36]$} \\
Arthrogryposis & \\
Intrauterine growth restriction & \\
Pulmongenital contractures & {$[36]$} \\
Craniofacial malformations & \\
\hline
\end{tabular}


in AG129 mice, which presented ocular pathology, demonstrating that the virus present in the eye remains infectious. This group also tested the prevalence of the virus in the eyes of congenitally infected offspring but only $5 \%$ of eyes remained positive for viral RNA [67].

These findings suggest that the eye can support viral replication 3 weeks after infection, which brings to attention a different non-vector transmission of ZIKV. Nevertheless, the mechanism of eye infection remains uncertain. Double knockout mice to the receptors previously described as required to ZIKV infection showed no difference levels of ZIKV present in the eyes and other organs $[27,40]$. Thus, the experimental models developed are essential to elucidate the path through which ZIKV reaches the eyes and causes damage [38].

\section{Conclusion}

ZIKV epidemics has reminded us the fragility of the human beings to emerging infectious diseases, as previously experienced with many other agents. Moreover, ZIKV also changed the way researchers and physicians deal with flavivirus infections. This is due mainly to the severe impact of ZIKV infection during pregnancy and the resulting CZS, with microcephaly, arthrogryposis and retinal damage (Table 1). Moreover, it may be sexually transmitted, which has never been observed for a flavivirus. Researchers have a long road to a better understanding of the molecular and cellular mechanisms behind the CZS and to the development of effective therapeutic interventions or vaccine approaches. These must be considered a priority, not only to stop the spreading of the virus and the dramatic impact of microcephaly, but also to prepare us for further epidemics.

\section{Abbreviations \\ C: Capside; CHIKV: Chikungunya vírus; CP: Cortical plate; CZS: Congenital Zika syndrome; DENV: Dengue virus; Env: Envelope; GBS: Guillain-Barré syndrome; HIV: Human immunodeficiency virus; IFNAR1: Interferon alfa receptor; ISGs: Interferon stimulating genes; IURG: Intrauterine growth restriction; JEV: Japanese Encephalytis; LV: Lateral ventricle; MAC-ELISA: IgM antibody- capture Elisa; NPCs: Neuronal precursor cells; NS1, NS2a-2b, NS3, NS4a-4b, NS5: Non-structural proteins; PHEIC: Public Health Emergency of International Concern; Pr-M: Pre-membrane; SVZ: Subventricular zone; \\ TORCHES: Toxoplasmosis, rubella, cytomegalovirus, herpes and syphilis; VZ: Ventricular zone; WHO: World Health Organization; WNV: West Nile virus; YFV: Yellow fever virus; ZIKV: Zika virus}

\section{Funding}

This work was supported by FAPESP process no. 2011/18703-2.

\section{Availability of data and materials}

Not applicable.

\section{Authors' contributions}

CMP delineated the topics and wrote introduction and microcephaly; CLF wrote about ocular alterations; NGZ wrote about arthrogryposis; and JPSP coordinated and corrected the manuscript. All authors read and approved the final version.
Ethics approval and consent to participate

Not applicable.

\section{Consent for publication}

Not applicable.

\section{Competing interests}

The authors declare that they have no competing interests.

\section{Publisher's Note}

Springer Nature remains neutral with regard to jurisdictional claims in published maps and institutional affiliations.

Received: 10 March 2017 Accepted: 1 September 2017

Published online: 15 September 2017

\section{References}

1. Oliveira Melo AS, Malinger G, Ximenes R, Szejnfeld PO, Alves Sampaio S, Bispo De Filippis AM. Zika virus intrauterine infection causes fetal brain abnormality and microcephaly: tip of the iceberg? Ultrasound Obstet Gynecol. 2016:47:6-7.

2. Calvet G, Aguiar RS, Melo AS, Sampaio SA, de Filippis I, Fabri A, et al. Detection and sequencing of Zika virus from amniotic fluid of fetuses with microcephaly in Brazil: a case study. Lancet Infect Dis. 2016;16(6):653-60.

3. Brasil P, Pereira JP, Moreira ME, Ribeiro Nogueira RM, Damasceno L, Wakimoto $\mathrm{M}$, et al. Zika virus infection in pregnant women in Rio de Janeiro. N Engl J Med. 2016;375:2321-34.

4. Cao-Lormeau VM, Blake A, Mons S, Lastère S, Roche C, Vanhomwegen J, et al. Guillain-Barré syndrome outbreak associated with Zika virus infection in French Polynesia: a case-control study. Lancet. 2016;387(10027):1531-9.

5. Dick GW, Kitchen SFHA. Zika virus. I. Isolations and serological specificity. Trans R Soc Trop Med Hyg. 1952;46(5):509-20.

6. Marchette NJ, Garcia R, Rudnick A. Isolation of Zika virus from Aedes aegypti mosquitoes in Malaysia. Am J Trop Med Hyg. 1969;18(3):411-5.

7. Kirya BG. A yellow fever epizootic in Zika forest, Uganda, during 1972: part 1: virus isolation and sentinel monkeys. Trans R Soc Trop Med Hyg. 1977; 71(3):254-60.

8. Kirya BG, Okia NO. A yellow fever epizootic in Zika Forest, Uganda, during 1972: part 2: monkey serology. Trans R Soc Trop Med Hyg. 1977;71(4):300-3.

9. Paixão ES, Barreto F, Teixeira MG, Costa MC, Rodrigues LC. History, epidemiology, and clinical manifestations of Zika: a systematic review. Am J Public Health. 2016;106(4):606-12.

10. Hamel R, Dejarnac O, Wichit S, Ekchariyawat P, Neyret A, Luplertlop N, et al. Biology of Zika virus infection in human skin cells. J Virol. 2015;89(17):8880-96.

11. Larocca RA, Abbink P, Peron JPS, Zanotto PM, lampietro MJ, BadamchiZadeh A, et al. Vaccine protection against Zika virus from Brazil. Nature. 2016;536(7617):474-8.

12. Abbink P, Larocca RA, De La Barrera RA, Bricault CA, Moseley ET, Boyd M, et al. Protective efficacy of multiple vaccine platforms against Zika virus challenge in rhesus monkeys. Science. 2016;353(6304):1129-32.

13. Liang Q, Luo Z, Zeng J, Chen W, Foo SS, Lee SA, et al. Zika virus NS4A and NS4B proteins deregulate Akt-mTOR signaling in human fetal neural stem cells to inhibit neurogenesis and induce autophagy. Cell Stem Cell. 2016; 19(5):663-71.

14. Grant A, Ponia SS, Tripathi S, Balasubramaniam V, Miorin L, Sourisseau M, et al. Zika virus targets human STAT2 to inhibit type I interferon signaling. Cell Host Microbe. 2016;19(6):882-90

15. Liu Y, Liu J, Du S, Shan C, Nie K, Zhang R, et al. Evolutionary enhancement of Zika virus infectivity in Aedes aegypti mosquitoes. Nature. 2017;545(7655):482-6.

16. Duffy MR, Chen TH, Hancock WT, Hayes EB, Powers AM, Kool JL, et al. Zika virus outbreak on Yap Island, Federated States of Micronesia. N Engl J Med. 2009;360:2536-43.

17. Falcao MB, Cimerman S, Luz KG, Chebabo A, Brigido HA, Lobo IM, et al. Management of infection by the Zika virus. Ann Clin Microbiol Antimicrob. 2016;15(1):57.

18. Cao-Lormeau VM, Roche C, Teissier A, Robin E, Berry AL, Mallet HP, et al. Zika virus, French Polynesia, south pacific, 2013. Emerg Infect Dis. 2014;20(6):1085-6. 
19. Wæhre T, Maagard A, Tappe D, Cadar D, Schmidt-Chanasit J. Zika virus infection after travel to Tahiti, December 2013. Emerg Infect Dis. 2014; 20(8):1412-4.

20. Roth A, Mercier A, Lepers C, Hoy D, Duituturaga S, Benyon E, et al. Concurrent outbreaks of dengue, chicungunya and Zica virus infections - an unprecedent epidemic wave of mosquito-borne viruses in the Pacific 20122014. Euro Surveill. 2014;19(41):1-8.

21. World Health Organization. Prevention of sexual transmission of Zika virus. Interim guidance update. 6 September 2016. WHO/ZIKV/MOC/16.1 Rev.3. http://apps.who.int/iris/bitstream/10665/204421/1/WHO_ZIKV_MOC_16.1_ eng.pdf. Accessed 1 Sept 2017.

22. Cauchemez S, Besnard M, Bompard P, Dub T, Guillemette-Artur P, Eyrolle-Guignot D, et al. Association between Zika virus and microcephaly in French Polynesia, 2013-15: a retrospective study. Lancet. 2016;387:2125-32.

23. Brasil. Ministério da Saúde. Centro de Operações de Emergências em Saúde Pública (COES). Informe epidemiológico nº 15. http://combateaedes.saude. gov.br/images/pdf/informe_microcefalia_ēeidemiologico15.pdf. Accessed on 1 Sept 2017.

24. Ventura CV, Maia M, Dias N, Ventura LO, Belfort R Jr. Zika: neurological and ocular findings in infant without microcephaly. Lancet. 2016; 387(10037):2502

25. Mlakar J, Korva M, Tul N, Popović M, Poljšak-Prijatelj M, Mraz J, et al. Zika virus associated with microcephaly. N Engl J Med. 2016;374(10):951-8.

26. de Araújo TVB, Rodrigues LC, de Alencar Ximenes RA, de Barros M-FD, Montarroyos UR, de Melo APL, et al. Association between Zika virus infection and microcephaly in Brazil, January to may, 2016: preliminary report of a case-control study. Lancet. 2016;16(12):1356-63.

27. Adibi JJ, Marques ET Jr, Cartus A, Beigi RH. Teratogenic effects of the Zika virus and the role of the placenta. Lancet. 2016;387(10027):1587-90.

28. Ventura CV, Maia M, Bravo-Filho V, Góis AL, Belfort R Jr. Zika virus in Brazil and macular atrophy in a child with microcephaly. Lancet. 2016;387(10015):228.

29. Bhatnagar J, Rabeneck DB, Martines RB, Reagan-Steiner S, Ermias Y, Estetter LBC, et al. Zika virus RNA replication and persistence in brain and placental tissue. Emerg Infect Dis. 2017;23(3):405-14.

30. Miner JJ, Cao B, Govero J, Smith AM, Fernandez E, Cabrera OH, et al. Zika virus infection during pregnancy in mice causes placental damage and fetal demise. Cell. 2016;165(5):1081-91.

31. Li C, Xu D, Ye Q, Hong S, Jiang Y, Liu X, et al. Zika virus disrupts neural progenitor development and leads to microcephaly in mice. Cell Stem Cell. 2016;19(1):120-6.

32. Cugola FR, Fernandes IR, Russo FB, Freitas BC, Dias JLM, Guimarães KP, et al. The Brazilian Zika virus strain causes birth defects in experimental models. Nature. 2016;534(7606):267-71.

33. Soares de Oliveira-Szejnfeld P, Levine D, ASO M, MMR A, AGM B, Chimelli L, et al. Congenital brain abnormalities and Zika virus: what the radiologist can expect to see prenatally and postnatally. Radiology. 2016;281(1):203.

34. Melo AS, Aguiar RS, Amorim MMR, Arruda MB, Melo FO, Ribeiro STC, et al. Congenital Zika virus infection: beyond neonatal microcephaly. J Am Med Assoc Neurol. 2016;73(12):1407-16.

35. Martines RB, Bhatnagar J, de Oliveira Ramos AM, Davi HPF, Iglezias SDA Kanamura CT, et al. Pathology of congenital Zika syndrome in Brazil: a case series. Lancet. 2016;388(10047):898-904.

36. Štrafela P, Vizjak A, Mraz J, Mlakar J, Pižem J, Tul N, et al. Zika virusassociated micrencephaly: a thorough description of neuropathologic findings in the fetal central nervous system. Arch Pathol Lab Med. 2017;141(1):73-81.

37. Soares de Souza A, Moraes Dias C, Braga FDCB, Terzian ACB, Estofolete CF, Oliani $\mathrm{AH}$, et al. Fetal infection by Zika virus in the third trimester: report of 2 cases. Clin Infect Dis. 2016;63(12):1622-5.

38. Nowakowski TJ, Pollen AA, Di Lullo E, Sandoval-Espinosa C, Bershteyn $M$, Kriegstein AR. Expression analysis highlights $A X L$ as a candidate Zika virus entry receptor in neural stem cells. Cell Stem Cell. 2016; 18(5):591-6.

39. Mccarthy M. Zika congenital syndrome is seen in infants whose mothers had asymptomatic infection. BMJ. 2016;353:i3416.

40. Alvarado MG, Schwartz DA. Zika virus infection in pregnancy, microcephaly, and maternal and fetal health: what we think, what we know, and what we think we know. Arch Pathol Lab Med. 2017;141(1):26-32.

41. Schwartz DA. Autopsy and postmortem studies are concordant: pathology of Zika virus infection is neurotropic in fetuses and infants with microcephaly following transplacental transmission. Arch Pathol Lab Med. 2017;141(1):68-72.

42. Hall JG. Arthrogryposis multiplex congenita: etiology, genetics, classification, diagnostic approach, and general aspects. J Pediat Orthop B. 1997;6(3):159-66.

43. Gurnett CA, Desruisseau DM, McCall K, Choi R, Meyer ZI, Talerico M, et al. Myosin binding protein C1: a novel gene for autosomal dominant distal arthrogryposis type 1. Hum Mol Genet. 2010;19(7):1165-73.

44. Kimber E, Tajsharghi H, Kroksmark AK, Oldfors A, Tulinius M. A mutation in the fast skeletal muscle troponin I gene causes myopathy and distal arthrogryposis. Neurology. 2006;67(4):597-601.

45. Tajsharghi H, Kimber E, Kroksmark AK, Jerre R, Tulinius M, Oldfors A. Embryonic myosin heavy-chain mutations cause distal arthrogryposis and developmental myosin myopathy that persists postnatally. Arch Neurol. 2008;65(8):1083-90.

46. Kalampokas E, Kalampokas T, Sofoudis C, Deligeoroglou E, Botsis D. Diagnosing arthrogryposis multiplex congenita: a review. ISRN Obstet Gynecol. 2012;2012:264918.

47. Bamshad M, Van Heest AE, Pleasure D. Arthrogryposis: a review and update. J Bone Joint Surg Am. 2009;91(Suppl 4):40-6.

48. Fraser SH, O'Keefe RJ, Scurry JP, Watkins AM, Drew JH, Chow CW. Hydrocephalus ex vacuo and clasp thumb deformity due to congenital cytomegalovirus infection. J Paediatr Child Health. 1994;30(5):450-2.

49. Hall JG. Arthrogryposis (multiple congenital contractures): diagnostic approach to etiology, classification, genetics, and general principles. Eur J Med Genet. 2014;57(8):464-72.

50. Kowalczyk B, Feluś J. Arthrogryposis: an update on clinical aspects, etiology, and treatment strategies. Arch Med Sci. 2016;12(1):10-24.

51. Fedrizzi E, Botteon G, Inverno M, Ciceri E, D'Incerti L, Dworzak F. Neurogenic arthrogryposis multiplex congenita: clinical and MRI findings. Pediatr Neurol. 1993;9(5):343-8.

52. van der Linden $V$, Filho ELR, Lins OG, van der Linden A, Aragão MFW, Brainer-Lima AM, et al. Congenital Zika syndrome with arthrogryposis: retrospective case series study. BMJ. 2016;354:13899.

53. Schuler-Faccini L, Ribeiro EM, Feitosa IML, Horovitz DDG, Cavalcanti DP, Pessoa A, et al. Possible association between Zika virus infection and microcephaly - Brazil, 2015. Morb Mortal Wkly Rep. 2016;65(3):59-62.

54. Sarno M, Sacramento GA, Khouri R, do Rosário MS, Costa F, Archanjo G, et al. Zika virus infection and stillbirths: a case of Hydrops Fetalis, Hydranencephaly and Fetal demise. PLoS Negl Trop Dis. 2016;10(2):e0004517.

55. Perez S, Tato R, Cabrera JJ, Lopez A, Robles O, Paz E, et al. Confirmed case of Zika virus congenital infection, Spain, march 2016. Euro Surveill. 2016; 21(24) doi:10.2807/1560-7917.ES.2016.21.24.30261.

56. de Paula FB, de Oliveira Dias JRJ, Prazeres J, Sacramento GAG, Ko Al, Maia MM, et al. Ocular findings in infants with microcephaly associated with presumed Zika virus congenital. J Am Med Assoc Ophthalmol. 2016; doi:10.1001/jamaophthalmol.2016.0267.

57. Ventura CV, Maia M, Ventura BV, Linden W, Araújo EB, Ramos RC, et al. Ophthalmological findings in infants with microcephaly and presumable intra-uterus Zika virus infection. Arq Bras Oftalmol. 2016;79(1):1-3.

58. Dias JRO, Ventura CV, Borba PD, Freitas BP, Pierroti LC, Nascimento AP, et al. Infants with congenital Zika syndrome and ocular findings from São Paulo, Brazil: spread of infection. Retin Cases Brief Rep. 2017; doi:10.1097//CB.0000000000000518.

59. Donadeu M, Lightowlers MW, Fahrion AS, Kessels J, Abela-Ridder B. Relevé épidémiologique hebdomadaire. Wkly Epidemiol Rec. 2009;3:445-52.

60. Kaur S, Jain S, Sodhi HBS, Rastogi A, Kamlesh. Optic nerve hypoplasia. Oman J Ophthalmol. 2013;6(2):77-82.

61. Ventura CV, Maia M, Travassos SB, Martins $\Pi$, Patriota F, Nunes ME, et al. Risk factors associated with the ophthalmoscopic findings identified in infants with presumed Zika virus congenital infection. J Am Med Assoc Ophthalmol. 2016;134(12):912-8.

62. Ventura CV, Fernandez MP, Gonzalez IA, Rivera-Hernandez DM, LopezAlberola $\mathrm{R}$, Peinado $\mathrm{M}$, et al. First travel-associated congenital Zika syndrome in the US: ocular and neurological findings in the absence of microcephaly. Ophthalmic Surg Lasers Imaging Retina. 2016;47(10): 952-5.

63. Petersen LR, Jamieson DJ, Powers AM, Honein MA. Zika Virus. N Engl J Med. 2016;374(16):1552-63.

64. Furtado JM, Espósito DL, Klein TM, Teixeira-Pinto T, da Fonseca BA. Uveitis associated with Zika virus infection. N Engl J Med. 2016;375(4):394-6. 
65. Fontes BM. Zika virus-related hypertensive iridocyclitis. Arq Bras Oftalmol. 2016;79(1):63.

66. Swaminathan S, Schlaberg R, Lewis J, Hanson KE, Couturier MR. Fatal Zika virus infection with secondary nonsexual transmission. N Engl J Med. 2016; 375(19):1907-9.

67. Miner JJ, Sene A, Richner JM, Smith AM, Santeford A, Ban N, et al. Zika virus infection in mice causes panuveitis with shedding of virus in tears. Cell Rep. 2016;16(12):3208-18.

Submit your next manuscript to BioMed Central and we will help you at every step:

- We accept pre-submission inquiries

- Our selector tool helps you to find the most relevant journal

- We provide round the clock customer support

- Convenient online submission

- Thorough peer review

- Inclusion in PubMed and all major indexing services

- Maximum visibility for your research

Submit your manuscript at www.biomedcentral.com/submit 